\title{
DIRETRIZES CURRICULARES NACIONAIS PARA A FORMAÇÃO INICIAL E CONTINUADA DOS PROFISSIONAIS DO MAGISTÉRIO DA EDUCAÇÃO BÁSICA: CONCEPÇÕES E DESAFIOS
}

\author{
Luiz Fernandes Dourado*
}

\begin{abstract}
RESUMO: $\mathrm{O}$ artigo apresenta as novas diretrizes curriculares nacionais para a formaçáo inicial e continuada dos profissionais do magistério da educação básica, tendo por base o Parecer CNE/CP 02/2015, aprovado pelo Conselho Pleno do Conselho Nacional de Educação (CNE), em 9 de junho de 2015, e homologado pelo MEC em 24 de junho de 2015. Situa que o processo de construçáo dessas novas DCNs - objeto de discussóes e debates a mais de uma década no CNE, por meio de Comissão Bicameral, ao considerar as diferentes concepçóes em disputas no campo, estudos e pesquisas sobre a temática, os marcos legais com destaque para a CF 1988, a LDB e o Plano Nacional de Educação (2014/214), bem como as deliberaçóes das Conferências Nacionais de Educação (Conae, 2010 e 2014) - objetivou garantir maior organicidade para a formaçáo inicial e continuada dos profissionais para o magistério da educação básica.
\end{abstract}

Palavras-chave: Diretrizes curriculares; Formaçáo Inicial e Continuada; Valorização; Educação básica.

\section{NATIONAL CURRICULUM GUIDELINES FOR INITIAL TRAINING AND CONTINUING EDUCATION FOR TEACHING PROFESSIONALS IN BASIC EDUCATION: CONCEPTS AND CHALLENGES}

ABSTRACT: The article presents the new national curriculum guidelines for initial and continuing training for teaching professionals in Basic Education, based on the National Council for Education (CNE) decision (CNE/CP 02/2015), as approved by the Plenary Board of the National Education Council, on June 9th, 2015, and approved by MEC (Ministry of Education) on June 24th, 2015. It considers the process of building these new National Curriculum Guidelines - objects of discussion and debate for more than a decade in the National Education Council. This was carried out by a Bicameral Commission which

\footnotetext{
* Universidade Federal de Goiás e Membro da Câmara de Educação Superior do Conselho Nacional de Educação. E-mail de contato: luizdourado1@gmail.com.
} 
considered the different conceptions and disputes in the field, studies and research on the subject, the legal frameworks highlighting the CF 1988, the LDB and the National Education Plan (2014/214) as well as the resolutions of the National Conference on Education (CONAE, 2010 and 2014) - aiming to ensure greater organic structure to the initial and continuing education of basic education teaching professionals.

Keywords: Curriculum guidelines; Initial and continuing training; Valuation; Basic education.

\section{DIRECTIVES DES PROGRAMMES NATIONAUX POUR LA FORMATION INITIALE ET CONTINUE DES PROFESSIONNELS ENSEIGNANTS DE L'EDUCATION BASIQUE: CONCEPTIONS ET DÉFIS}

RÉSUMÉ: L'article présente les nouvelles directives des programmes nationaux de la formation initiale et continue des professionnels de l'éducation basique, en se basant sur le Rapport CNE/CP 02/2015, approuvé par le Conseil Plénier du Conseil National d'Education (CNE), le 9 juin 2015 et homologué par le MEC le 24 juin 2015. Il rend compte du fait que le processus de construction DCN's, objet de discussions et de débats il y a plus d'une décennie, via une Commission à deux chambres, considérant les différentes conceptions en dispute dans le domaine, les études et les recherches sur ce théme, les aspects légaux, en particulier la CF 1988, la LDB et le Plan National d'Education (2014/214), tout comme les délibérations des Conférences Nationales d'Education (CONAE, 2010 e 2014) - a eu pour obectif de garantir une meilleure organisation de la formation initiale et continue des professionnels enseignants de l'éducation de base.

Mots-clés: Formation iniciale et continue; Valorisation; Éducation basique; Directives de programmes.

\section{A formação de profissionais do magistério da educação básica: organicidade e institucionalização}

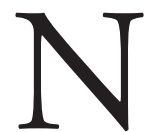

a última década, vários movimentos se efetivaram direcionados a repensar a formação de profissionais do magistério da educação básica, incluindo questôes e proposições atinentes à valorização desses profissionais. No âmbito do $\mathrm{CNE}$, houve movimentação em direção à busca de maior organicidade para a formação de profissionais do magistério da educação básica, incluindo a rediscussão das Diretrizes e outros instrumentos normativos acerca da formação inicial e continuada ${ }^{1}$. 
Merece ser ressaltado que as deliberaçóes da Conae cumpriram papel singular nesse processo ao destacar a articulação entre Sistema Nacional de Educação, as políticas e a valorização dos profissionais da educação, bem como ao reafirmar uma base comum nacional para a formação inicial e continuada cujos princípios devem ser considerados na formulação dos projetos institucionais de formaçáo inicial e continuada - incluindo a licenciatura - por meio da garantia de concepção de formação pautada tanto pelo desenvolvimento de sólida formação teórica e interdisciplinar em educação de crianças, adolescentes, jovens e adultos(as) e nas áreas específicas de conhecimento científico quanto pela unidade entre teoria e prática e pela centralidade do trabalho como princípio educativo na formação profissional, como também pelo entendimento de que a pesquisa se constitui em princípio cognitivo e formativo e, portanto, eixo nucleador dessa formação. Importante ressaltar que tais concepçóes, historicamente, vêm sendo defendidas por entidades da área, especialmente, Anfope, Anpae, Anped, Cedes e Forumdir.

A aprovação do Plano Nacional de Educação pelo Congresso Nacional e a sanção Presidencial, sem vetos, que resultaram na Lei no 13.005/2014, inauguraram uma nova fase para as políticas educacionais brasileiras. Além das diretrizes que são sinalizadoras de busca de maior organicidade para a educação nacional no decênio 2014/2024, o PNE apresenta 20 metas e várias estratégias que englobam a educação básica e a educação superior, em suas etapas e modalidades, a discussão sobre qualidade, avaliação, gestão, financiamento educacional e valorização dos profissionais da educação.

As metas, especialmente as metas 12,15,16,17 e 18, e suas estratégias, articuladas às Diretrizes do PNE, ao estabelecerem os nexos constituintes e constitutivos para as políticas educacionais, devem ser consideradas na educação em geral e, em particular, na educação superior e, portanto, base para a formação inicial e continuada dos profissionais da educação, objetivando a melhoria desse nível de ensino e sua expansão.

Todas essas metas e estratégias incidem nas bases para a efetivação de uma política nacional de formação dos profissionais da educação e foram consideradas nas diretrizes curriculares nacionais para a formação inicial e continuada dos profissionais do magistério. Essa política, como definido na Meta 15, visa garantir maior organicidade à formação dos profissionais da educação, incluindo o magistério. Assim, a Política Nacional de Formação dos Profissionais da Educação Básica $^{2}$, tem por finalidade organizar e efetivar, em regime de colaboração entre a União, os Estados, o Distrito Federal e os Municípios, em estreita articulação com os sistemas, redes e instituições de educação básica e superior, a formação dos profissionais da educação básica. Essa política nacional, a ser coordenada pelo $\mathrm{MEC}$, se constituiu como componente essencial à profissionalização docente. 
Essa política nacional, em articulação com a Meta 12 do PNE, que prevê a ampliação efetiva de vagas na educação superior, definindo que $40 \%$ destas vagas deverão ser oferecidas pelo setor público, deverá contar com Comitê gestor da política nacional com a finalidade de estabelecer planos estratégicos, prevendo açôes e programas a serem apoiados técnica e financeiramente pelo MEC, bem como contrapartidas e compromissos a serem assumidos pelas Secretarias Estaduais e Municipais de Educação. Nessa direção, em consonância com a política nacional, compete ao poder público priorizar, na expansão projetada pelo PNE (40\% das vagas no setor público), a formação dos profissionais da educação por meio de suas instituiçóes de educação superior.

\section{O CNE e a formação de profissionais do magistério da educação básica: o processo de construção das novas DCNs}

As discussões e estudos sobre a formação dos profissionais do magistério para a educação básica tem sido objeto de debates ao longo da trajetória do Conselho Nacional de Educação (CNE). Tal processo, retomado nos anos 90, resultou na aprovação de várias Resoluçóes direcionadas a formação desses profissionais ${ }^{3}$. Como decorrência desse processo e considerando a complexidade da temática e os vários embates subjacentes à mesma o CNE criou Comissão bicameral para estudo da matéria.

Assim, o Conselho Nacional de Educação designou Comissão Bicameral de Formação de Professores, formada por conselheiros da Câmara de Educação Superior e da Câmara de Educação Básica, com a finalidade de desenvolver estudos e proposiçóes sobre a temática. Importante destacar que essa Comissão, em função da renovação periódica dos membros do $\mathrm{CNE}$, foi, várias vezes, recomposta (Portaria CNE/CP no 2, de 15 de setembro de 2004; Portaria CNE/CP no 3, de 20 de setembro de 2007; Portaria CNE/CP no 1, de 9 de outubro de 2008; Portaria $\mathrm{CNE} / \mathrm{CP}$ n$^{\circ}$ 9, de $1^{\circ}$ de junho de 2009; Portaria CNE/CP no 1, de 18 de junho de 2010). Em 2012, a Comissão Bicameral foi recomposta e oficializada na reunião do CP/CNE em 4 de setembro de 2012 e, novamente, recomposta por meio da Portaria CNE/CP no 1,28 de janeiro de $2014^{4}$.

A Comissão recomposta em 2014 retomou os estudos desenvolvidos pelas comissóes anteriores, aprofundou os estudos e as discussóes sobre as normas gerais e as práticas curriculares vigentes nas licenciaturas, bem como sobre a situação dos profissionais do magistério face às questóes de profissionalização, com destaque para a formação inicial e continuada, e definiu como horizonte propositivo de sua atuação a discussão e a proposição de Diretrizes Curriculares Nacionais para a Formação Inicial e Continuada dos Profissionais do Magistério da Educação Básica 5 . Em 2014, após nova renovação dos membros do CNE, a 
Comissão, por meio da Portaria CNE/CP no 6, de 2 de dezembro de 2014, foi novamente recomposta ${ }^{6}$. Considerando que boa parte dos membros da Comissão anterior foi mantida, e visando avançar os trabalhos iniciados, a Comissão prosseguiu suas atividades e submeteu nova versão de documento base e proposta de minuta das DCNs para discussão pública, envolvendo reuniōes ampliadas, debates e participação em eventos sobre a temática. Essa rodada de discussóes, ao longo de 2014, propiciou críticas e sugestóes, por meio de debates no CNE e em outros espaços em que conselheiros da Comissão Bicameral do CNE foram convidados. ${ }^{7}$

Merece ser ressaltado o papel assumido pela Comissão Bicameral como protagonista desse processo, ao realizar inúmeras reunióes de trabalho, atividades, estudos, produção e discussão de textos desenvolvidos pelos membros da Comissão. (ALVES, 2013a, 2014; DOURADO, 2013, 2014; GOMES, 2013; LIMA, 2013, 2013a; SANDER, 2013; TUTTMAN, 2013) Estes textos e os estudos e pesquisas desenvolvidos (DOURADO, 2009; SHEIBE, 2009; BORDAS, 2009; DAMIES, 2012) a partir de demanda da Comissão Bicameral de Formação de Professores, no âmbito do Projeto CNE/UNESCO "Subsídio à Formulação e Avaliação de Políticas Educacionais Brasileiras”, constituíram subsídios para o delineamento da referida proposta de Diretrizes à medida em que propiciaram elementos analíticos e propositivos substantivos concernentes à necessidade de consolidação das normas e diretrizes, análises dos cursos de licenciatura - inclusive a pedagogia - e avaliação de sua efetivação, bem como por sinalizaçóes e proposiçôes sobre as dinâmicas formativas, princípios, perfil, núcleos de estudos e eixos de formação, dentre outros.

Com o processo de trabalho intensificado a partir da aprovação do Plano Nacional de Educação (Lei no 13.005/2014), a Comissão realizou várias reuniôes e discussóes. É importante salientar, ainda, a participação de membros da Comissão nas conferências municipais, estaduais e nacional, onde a temática da formação esteve presente no eixo VI nos documentos referencial, base e final da Conae 2014. Além dessas atividades, destacam-se reunióes com instituiçóes de educação superior, conselhos estaduais de educação, participação de membros da comissão em eventos ${ }^{8}$, abordando as DCNs para a formação de profissionais da educação, e em atendimento a diversas demandas da comunidade educacional para discussão das novas DCNs propostas. Ao longo desse processo a participação das entidades acadêmico-científicas e sindicais foi efetiva. Após todo esse processo de ampla discussão, foi disponibilizada pela Comissão, para audiência pública, proposta de DCNs que foi sendo consolidada. A audiência pública foi realizada em sessão específica do Conselho Pleno para tratar da temática, no dia 6 de abril de 2015, na cidade do Recife/PE. Nessa ocasião, as manifestações, envolvendo diferentes interlocutores, destacaram a importância e os avanços presentes na proposta das DCNs e foram apresentadas, ainda, sugestóes de alteraçóes visando reforçar concepçóes e proposiçóes contidas no referido documento. Após essa eta- 
pa da audiência pública, foi apresentada e discutida nova proposta de DCNs, na qual foram incorporadas contribuiçóes da audiência pública e também de outros documentos e sugestóes recebidas. A Comissão Bicameral aprovou o texto, por unanimidade, em 4 de maio de 2015, para apresentação, discussão e deliberação no Conselho Pleno do CNE. Em 5 de maio de 2015, em sessão ordinária do Conselho Pleno, o trabalho da Comissão foi apresentado pelo Relator e, em decorrência desse processo, foi proposta e aprovada, por unanimidade, pelos membros do Conselho Pleno do $\mathrm{CNE}$, a realização de uma reunião extraordinária deste Conselho para deliberação sobre o Parecer e a minuta de Resolução sobre a matéria. Nessa direção, a reunião deliberativa foi agendada para o dia 9 de junho de 2015 e nesta data o Parecer ${ }^{9}$ e, consequentemente, a minuta de Resolução foi aprovado por unanimidade pelos membros do Conselho Pleno do Conselho Nacional e encaminhado para o Ministério da Educação que os homologou, sem alteraçóes, no dia 24 de junho de 2015 em sessão pública no MEC.

\section{As novas diretrizes curriculares nacionais (DCNs) para a formação inicial e continuada dos profissionais do magistério}

É importante salientar que a formação de profissionais do magistério da educação básica tem se constituído em campo de disputas de concepçóes, dinâmicas, políticas, currículos. De maneira geral, a despeito das diferentes visôes, os estudos e pesquisas, já mencionados, apontam para a necessidade de se repensar a formação desses profissionais. Nessa direção, considerando a legislação em vigor, com especial realce para o PNE, suas metas e estratégias, após amplo estudo e discussões com diferentes atores, e considerando a definição da Comissão Bicameral no sentido de encaminhar diretrizes conjuntas para a formação inicial e continuada dos profissionais do magistério da educação básica, bem como as políticas voltadas para maior organicidade desta formação e as deliberaçóes da Conae (2010 e 2014), as novas DCNs aprovadas pelo CP/CNE, em 09.6.15, e sancionadas pelo MEC, em 24.6.15, apresentam os seguintes considerandos como aportes e concepçóes fundamentais para a melhoria da formação inicial e continuada e suas dinâmicas formativas:

1. A consolidação das normas nacionais para a formação de profissionais do magistério para a educação básica é indispensável para o projeto nacional da educação brasileira, em seus níveis e suas modalidades da educação básica, tendo em vista a abrangência e a complexidade da educação de modo geral e, em especial, a educação escolar inscrita na sociedade;

2. A concepção sobre conhecimento, educação e ensino é basilar para garantir o projeto da educação nacional, superar a fragmentação das políticas públicas e a desarticulação institucional por meio da instituição do Sistema Nacional de 
Educação, instituído no bojo de relações de cooperação e colaboração entre entes federados e sistemas educacionais;

3. A igualdade de condiçóes para o acesso e a permanência na escola; a liberdade de aprender, ensinar, pesquisar e divulgar a cultura, o pensamento, a arte e o saber; o pluralismo de ideias e de concepções pedagógicas; o respeito à liberdade e o apreço à tolerância; a valorização do profissional da educação; a gestão democrática do ensino público; a garantia de um padrão de qualidade; a valorização da experiência extraescolar; a vinculação entre a educação escolar, o trabalho e as práticas sociais; o respeito e a valorização da diversidade étnico-racial, entre outros, constituem princípios vitais para a melhoria e democratização da gestão e do ensino;

4. As instituiçôes educativas nas diferentes etapas (educação infantil, ensino fundamental e ensino médio) e modalidades da educação básica cumprem, sob a legislação vigente, um papel estratégico na formação requerida pelos níveis de ensino cujo eixo de atuação são os projetos pedagógicos;

5. A necessidade de articular as Diretrizes Curriculares Nacionais para a Formação Inicial e Continuada, em Nível Superior, e as Diretrizes Curriculares Nacionais para a Educação Básica;

6. Os princípios que norteiam a base comum nacional para a formação inicial e continuada, tais como: a) sólida formação teórica e interdisciplinar; b) unidade teoria-prática; c) trabalho coletivo e interdisciplinar; d) compromisso social e valorizaçáo do profissional da educação; e) gestão democrática; f) avaliação e regulaçâao dos cursos de formação;

7. A articulação entre graduação e pós-graduação e entre pesquisa e extensão como princípio pedagógico essencial ao exercício e aprimoramento do profissional do magistério e da prática educativa;

8. A docência como ação educativa e como processo pedagógico intencional e metódico, envolvendo conhecimentos específicos, interdisciplinares e pedagógicos, conceitos, princípios e objetivos da formação que se desenvolvem na socialização e construção de conhecimentos, no diálogo constante entre diferentes visóes de mundo;

9. O currículo como o conjunto de valores propício à produção e à socialização de significados no espaço social e que contribui para a construção da identidade sociocultural do educando, dos direitos e deveres do cidadão, do respeito ao bem comum e à democracia, às práticas educativas formais e não formais e à orientação para o trabalho;

10. A realidade concreta dos sujeitos que dão vida ao currículo e às instituiçóes de educação básica, sua organização e gestão, os projetos e cursos de formação, devem ser contextualizados no espaço e no tempo e atentos às características das crianças, adolescentes, jovens e adultos que justificam e instituem a vida da/e na escola, bem como, possibilitar a compreensão e reflexão sobre as relaçóes entre a vida, o conhecimento, a cultura, o profissional do magistério, o estudante e a instituição;

11. A educação em e para os direitos humanos é um direito fundamental constituindo uma parte do direito à educação e, também, uma mediação para 
efetivar o conjunto dos direitos humanos reconhecidos pelo Estado brasileiro em seu ordenamento jurídico e pelos países que lutam pelo fortalecimento da democracia; além disso, a educação em direitos humanos é uma necessidade estratégica na formação dos profissionais do magistério e na ação educativa em consonância com as Diretrizes Nacionais para a Educação em Direitos Humanos;

12. A importância do profissional do magistério e de sua valorização profissional, assegurada pela garantia de formação inicial e continuada, plano de carreira, salário e condiçôes dignas de trabalho;

13. O trabalho coletivo como dinâmica político-pedagógica que requer planejamento sistemático e integrado.

$\mathrm{Na}$ busca de maior organicidade das políticas, as novas DCNs enfatizam que estes processos implicam o repensar e o avançar nos marcos referenciais atuais para a formação inicial e continuada por meio de açôes mais orgânicas entre as políticas e gestão para a educação básica e a educação superior, incluindo a pós-graduação e, nesse contexto, para as políticas direcionadas à valorização dos profissionais da educação.

Por essa razão e articulados a esse movimento de busca de maior organicidade na formação de professores, em sintonia com o Documento Final da Conae (2014), princípios da Política Nacional de Formação de Profissionais do Magistério da Educação Básica, definidos no artigo 2º do Decreto nº 6.755/2009, as novas DCNs definem os princípios da formação inicial e continuada de profissionais do magistério da educação básica e sinalizam para maior organicidade nos projetos formativos, necessidade de maior articulação entre as instituições de educação superior e de educação básica, definindo que a formação inicial e continuada deve contemplar:

I. Sólida formação teórica e interdisciplinar dos profissionais;

II. A inserção dos estudantes de licenciatura nas instituiçôes de educação básica da rede pública de ensino, espaço privilegiado da práxis docente;

III. O contexto educacional da região onde será desenvolvido;

IV. Atividades de socialização e avaliação dos impactos;

V. Aspectos relacionados à ampliação e ao aperfeiçoamento do uso da língua portuguesa e à capacidade comunicativa, oral e escrita, como elementos fundamentais da formação dos professores e à aprendizagem de Libras;

VI. Questôes socioambientais, éticas, estéticas e relativas a diversidade étnico-racial, de gênero, sexual, religiosa, de faixa geracional e sociocultural como princípios de equidade. 
De igual modo, as novas DCNs enfatizam a necessária organicidade no processo formativo e sua institucionalização ao entender que o projeto de formação deve ser elaborado e desenvolvido por meio da articulação entre a instituição de educação superior e o sistema de ensino e instituiçóes de educação básica, envolvendo a consolidação de Fóruns Estaduais e Distrital Permanentes de Apoio à Formação Docente, em regime de cooperação e colaboraçáo. Tais questôes implicam novos horizontes à dinâmica formativa dos profissionais do magistério da educação básica, pois a garantia do direito à educação a grupos e sujeitos historicamente marginalizados exige transformação na forma como as instituições de educação básica e superior estruturam seus espaços e tempos, suas regras e normas, incorporam novos materiais e recursos pedagógicos.

Para atender a essa concepção articulada de formação inicial e continuada, as novas DCNs definem que é fundamental que as instituiçôes formadoras institucionalizem projeto de formação com identidade própria, em consonância com o Plano de Desenvolvimento Institucional (PDI), o Projeto Pedagógico Institucional (PPI) e o Projeto Pedagógico de Curso (PPC).

Considerando a importância da formação continuada oferecida pelos centros de formação de estados e municípios, bem como pelas instituiçóes educativas de educação básica, as novas DCNs reconhecem esse lócus de formação continuada como parte constitutiva da nova política que se quer consolidar no país.

Outra definição fundamental para a melhoria da formação de profissionais do magistério consiste na garantia de base comum nacional, sem prejuízo de base diversificada, pautada pela concepção de educação como processo emancipatório e permanente, bem como pelo reconhecimento da especificidade do trabalho docente, que conduz à práxis como expressão da articulação entre teoria e prática e à exigência de que se leve em conta a realidade dos ambientes das instituiçóes educativas da educação básica e da profissão. Nessa direção, as novas DCNs definem que o(a) egresso(a) da formação inicial e continuada deverá possuir um repertório de informaçóes e habilidades composto pela pluralidade de conhecimentos teóricos e práticos, resultado do projeto pedagógico e do percurso formativo vivenciado cuja consolidação virá do seu exercício profissional, fundamentado em princípios de interdisciplinaridade, contextualização, democratização, pertinência e relevância social, ética e sensibilidade afetiva e estética, de modo a lhe permitir: o conhecimento da instituição educativa; a pesquisa; atuaçáo profissional no ensino, na gestão de processos educativos e na organização e gestão de instituiçóes de educação básica. Nessa direção, o projeto de formação deve abranger diferentes características e dimensóes da iniciação à docência. 


\section{As novas DCNs e a formação inicial do magistério da educação básica em nível superior}

As novas DCNs, considerando o esforço que deverá ser realizado pelo Estado brasileiro, a partir de uma concepção de federalismo cooperativo e em consonância com a política nacional, definem que os cursos de formação inicial para os profissionais do magistério para a educação básica, em nível superior, compreendem:

I. Cursos de graduação de licenciatura;

II. Cursos de formação pedagógica para graduados não licenciados;

III. Cursos de segunda licenciatura.

Nessa direção, as novas DCNs definem que:

1. Compete à instituição formadora definir, no seu projeto institucional de formação, as formas de desenvolvimento da formação inicial dos profissionais do magistério da educação básica articuladas às políticas de valorização desses profissionais e em consonância ao Parecer CP/CNE 2/2015 e respectiva resoluçáo;

2. Que a formação inicial capacite o profissional do magistério da educação básica, para o exercício da docência e da gestão educacional e escolar na educação básica, o que vai requerer que essa formação em nível superior, adequada à área de conhecimento e às etapas e modalidades de atuaçáo, possibilite acesso a conhecimentos específicos sobre gestáo educacional e escolar, bem como formação pedagógica para o exercício da gestão e coordenação pedagógica e atividades afins.

3. Que a formação inicial de profissionais do magistério será ofertada, preferencialmente, de forma presencial, com elevado padrão acadêmico, científico e tecnológico e cultural.

Desse modo, depreende-se que a formação inicial se destina àqueles que pretendem exercer o magistério da educação básica em suas etapas e modalidades de educação e em outras áreas nas quais sejam previstos conhecimentos pedagógicos, compreendendo a articulação entre estudos teórico-práticos, investigação e reflexão crítica, aproveitamento da formação e experiências anteriores em instituiçóes de ensino.

Assim, as atividades do magistério também compreendem a atuação e participação na organização e gestão de sistemas de educação básica e suas instituiçóes de ensino, englobando o planejamento, desenvolvimento, coordenação, acompanhamento e avaliação de projetos, do ensino, das dinâmicas pedagógicas 
e experiências educativas, bem como, a produção e difusão do conhecimento científico-tecnológico das áreas específicas e do campo educacional.

Enfatizando a institucionalização da formação inicial dos profissionais do magistério para a educação básica, as novas DCNs definem que essa formação inicial proposta requer projeto com identidade própria de curso de licenciatura sem prescindir de articulação, no que couber, com os cursos de bacharelado ou tecnológico, a outra(s) licenciatura(s) ou a cursos de formação pedagógica de docentes.

Visando garantir diretrizes nacionais articuladas à trajetória das instituições formadoras, as novas DCNs definem que os cursos de formação inicial, respeitadas a diversidade nacional e a autonomia pedagógica das instituiçóes, constituir-se-ão dos seguintes núcleos:

I. Núcleo de estudos de formação geral, das áreas específicas e interdisciplinares, e do campo educacional, seus fundamentos e metodologias, e das diversas realidades educacionais;

II. Núcleo de aprofundamento e diversificação de estudos das áreas de atuação profissional, incluindo os conteúdos específicos e pedagógicos e a pesquisa priorizadas pelo projeto pedagógico das instituições, em sintonia com os sistemas de ensino; e

III. Núcleo de estudos integradores para enriquecimento curricular.

\section{As novas DCNs e a formação inicial do magistério da educação básica em nível superior: estrutura e currículo}

As novas DCNs definem a seguinte estrutura e currículo dos cursos de formação inicial. Os cursos de formação deverão garantir nos currículos conteúdos específicos da respectiva área de conhecimento ou interdisciplinares, seus fundamentos e metodologias, bem como conteúdos relacionados aos fundamentos da educação, formação na área de políticas públicas e gestão da educação, seus fundamentos e metodologias, direitos humanos, diversidades étnico-racial, de gênero, sexual, religiosa, de faixa geracional, Língua Brasileira de Sinais (Libras) e direitos educacionais de adolescentes e jovens em cumprimento de medidas socioeducativas.

Considerando a identidade do profissional do magistério da educação básica proposta, deverá ser garantida, ao longo do processo, efetiva e concomitante relação entre teoria e prática, ambas fornecendo elementos básicos para o desenvolvimento dos conhecimentos e habilidades necessários à docência. 
Importante apreender tais processos e, sobretudo, situar a concepção e o entendimento do papel da prática como componente curricular e do estágio supervisionado, resguardando a especificidade de cada um e sua necessária articulação, bem como a necessária supervisão desses momentos formativos

Os critérios de organização da matriz curricular, bem como a alocação de tempos e espaços curriculares, se expressam em eixos em torno dos quais se articulam dimensóes a serem contempladas.

Nas licenciaturas em educação infantil e anos iniciais do ensino fundamental, cursos de pedagogia, a serem desenvolvidos em projetos de cursos articulados, deverão preponderar os tempos dedicados à constituição de conhecimento sobre os objetos de ensino e, nas demais licenciaturas, o tempo dedicado às dimensóes pedagógicas não será inferior à quinta parte da carga horária total.

\section{A. Cursos de formação inicial de professores para a educação básica em nível superior, em cursos de licenciatura, organizados em áreas especializadas, por componente curricular ou por campo de conhecimento e/ou interdisciplinar}

Os cursos de formação inicial de professores para a educação básica em nível superior, em cursos de licenciatura, organizados em áreas especializadas, por componente curricular ou por campo de conhecimento e/ou interdisciplinar, considerando-se a complexidade e multirreferencialidade dos estudos que os englobam, bem como a formação para o exercício integrado e indissociável da docência na educação básica, incluindo o ensino e a gestão dos processos educativos escolares e não escolares, a produção e difusão do conhecimento científico, tecnológico e educacional, estruturam-se por meio da garantia de base comum nacional das orientaçóes curriculares, constituindo-se de, no mínimo, 3.200 (três mil e duzentas) horas de efetivo trabalho acadêmico, em cursos com duração de, no mínimo, 8 (oito) semestres ou 4 (quatro) anos, compreendendo:

a) 400 (quatrocentas) horas de prática como componente curricular, distribuídas ao longo do processo formativo;

b) 400 (quatrocentas) horas dedicadas ao estágio supervisionado, na área de formação e atuação na educação básica, contemplando também outras áreas específicas, se for o caso, conforme o projeto de curso da instituição;

c) pelo menos 2.200 (duas mil e duzentas) horas dedicadas às atividades formativas estruturadas pelos núcleos I e II, conforme o projeto de curso da instituição;

d) 200 (duzentas) horas de atividades teórico-práticas de aprofundamento em áreas específicas de interesse dos estudantes, como definido no núcleo III, por meio da iniciação científica, da iniciação à docência, da extensão e da monitoria, entre outras, conforme o projeto de curso da instituição. 


\section{B. Cursos de formação pedagógica para graduados não licenciados, de caráter emergencial e provisório}

Os cursos de formação pedagógica para graduados não licenciados, de caráter emergencial e provisório, ofertados a portadores de diplomas de curso superior formados em cursos relacionados à habilitação pretendida com sólida base de conhecimentos na área estudada, devem ter carga horária mínima variável de 1.000 (mil) a 1.400 (mil e quatrocentas) horas de efetivo trabalho acadêmico, dependendo da equivalência entre o curso de origem e a formação pedagógica pretendida.

A definição da carga horária deve respeitar os seguintes princípios:

I. quando o curso de formação pedagógica pertencer à mesma área do curso de origem, a carga horária deverá ter, no mínimo, 1.000 (mil) horas;

II. quando o curso de formação pedagógica pertencer a uma área diferente da do curso de origem, a carga horária deverá ter, no mínimo, 1.400 (mil e quatrocentas) horas;

III. a carga horária do estágio curricular supervisionado é de 300 (trezentas) horas;

IV. deverá haver 500 (quinhentas) horas dedicadas às atividades formativas referentes ao inciso I, estruturadas pelos núcleos I e II, conforme o projeto de curso da instituição;

V. deverá haver 900 (novecentas) horas dedicadas às atividades formativas referentes ao inciso II, estruturadas pelos núcleos I e II, conforme o projeto de curso da instituição;

VI. deverá haver 200 (duzentas) horas de atividades teórico-práticas de aprofundamento em áreas específicas de interesse dos alunos, como definido no núcleo III, conforme o projeto de curso da instituição.

Por se tratar de cursos de formação pedagógica para graduados não licenciados, de caráter emergencial e provisório, define-se o prazo máximo de 5 (cinco) anos para que o Ministério da Educação, em articulação com os sistemas de ensino e com os fóruns estaduais permanentes de apoio à formação, proceda à avaliação do desenvolvimento desses cursos de formação, definindo prazo para sua extinção em cada estado da federação.

\section{Cursos de segunda licenciatura}

Os cursos de segunda licenciatura, direcionados a profissionais já licenciados, terão carga horária mínima variável de 800 (oitocentas) a 1.200 (mil e duzentas) horas, dependendo da equivalência entre a formação original e a nova licenciatura. 
A definição da carga horária deve respeitar os seguintes princípios:

I. quando o curso de segunda licenciatura pertencer à mesma área do curso de origem, a carga horária deverá ter, no mínimo, 800 (oitocentas) horas;

II. quando o curso de segunda licenciatura pertencer a uma área diferente da do curso de origem, a carga horária deverá ter, no mínimo, 1.200 (mil e duzentas) horas;

III. a carga horária do estágio curricular supervisionado é de 300 (trezentas) horas.

Durante o processo formativo, deverá ser garantida efetiva e concomitante relação entre teoria e prática, ambas fornecendo elementos básicos para o desenvolvimento dos conhecimentos e habilidades necessários à docência.

Os cursos de segunda licenciatura poderão ser ofertados a portador de diploma de cursos de graduação em licenciatura, independentemente da área de formação. É condição institucional para a oferta dos cursos de segunda licenciatura que a instituição de educação superior oferte curso de licenciatura reconhecido e com avaliação satisfatória pelo MEC na habilitação pretendida, sendo dispensada a emissão de novos atos autorizativos

\section{As novas DCNs e a formação continuada dos profissionais do magistério}

Segundo as novas DCNs, a formação continuada compreende dimensóes coletivas, organizacionais e profissionais, bem como o repensar do processo pedagógico, dos saberes e valores, e envolve atividades de extensão, grupos de estudos, reuniōes pedagógicas, cursos, programas e ações para além da formação mínima exigida ao exercício do magistério na educação básica, tendo como principal finalidade a reflexão sobre a prática educacional e a busca de aperfeiçoamento técnico, pedagógico, ético e político do profissional docente.

A formação continuada decorre de concepção de desenvolvimento profissional dos profissionais do magistério que leva em conta:

I. os sistemas e redes de ensino, o projeto pedagógico das instituições de educação básica, bem como os problemas e os desafios da escola e do contexto onde ela está inserida;

II. a necessidade de acompanhar a inovaçáo e o desenvolvimento associados ao conhecimento, à ciência e à tecnologia;

III. o respeito ao protagonismo do professor e a um espaço-tempo que lhe permita refletir criticamente e aperfeiçoar sua prática; 
IV. o diálogo e a parceria com atores e instituiçóes competentes, capazes de contribuir para alavancar novos patamares de qualidade ao complexo trabalho de gestão da sala de aula e da instituição educativa.

A formação continuada deve se dar pela oferta de atividades formativas diversas incluindo atividades e cursos de atualização e extensão, cursos de aperfeiçoamento, cursos de especialização, cursos de mestrado e doutorado que agreguem novos saberes e práticas, articulados às políticas e gestão da educação, à área de atuação do profissional e às instituiçóes de educação básica, em suas diferentes etapas e modalidades. A formação continuada deve se efetivar por meio de projeto formativo que tenha por eixo a reflexão crítica sobre as práticas e o exercício profissional e a construção identitária do profissional do magistério.

Desse modo, as novas DCNs em consonância com a legislação, define que a formação continuada envolve:

I. atividades formativas organizadas pelos sistemas, redes e instituiçôes de educação básica incluindo desenvolvimento de projetos, inovaçôes pedagógicas, entre outros;

II. atividades e/ou cursos de atualização, com carga horária mínima de 20 (vinte) horas e máxima de 80 (oitenta) horas, por atividades formativas diversas, direcionadas à melhoria do exercício do docente;

III. atividades e/ou cursos de extensão, oferecidas por atividades formativas diversas, em consonância com o projeto de extensão aprovado pela instituição de educação superior formadora;

IV. cursos de aperfeiçoamento, com carga horária mínima de 180 (cento e oitenta) horas, por atividades formativas diversas, em consonância com o projeto pedagógico da instituição de educação superior;

V. cursos de especialização lato sensu por atividades formativas diversas, em consonância com o projeto pedagógico da instituição de educação superior e de acordo com as normas e resoluçóes do CNE;

VI. cursos ou programas de mestrado acadêmico ou profissional, por atividades formativas diversas, de acordo com o projeto pedagógico do curso/programa da instituição de educação superior, respeitadas as normas e resoluçóes do CNE e da Coordenação de Aperfeiçoamento de Pessoal de Nível Superior - Capes;

VII. cursos ou programas de doutorado, por atividades formativas diversas, de acordo com o projeto pedagógico do curso/programa da instituição de educação superior, respeitadas as normas e resoluçôes do CNE e da Capes.

A instituição formadora, em efetiva articulação com o planejamento estratégico do Fórum Estadual Permanente de Apoio à Formação Docente e com os sistemas e redes de ensino e com as instituiçôes de educação básica, definirá no seu projeto institucional as formas de desenvolvimento da formação continuada 
dos profissionais do magistério da educação básica, articulando-as às políticas de valorização a serem efetivadas pelos sistemas de ensino ${ }^{10}$.

\section{As novas DCNs e a valorização dos profissionais do magistério da educação básica}

As novas DCNs definem que os profissionais do magistério da educaçẫo básica compreendem aqueles que exercem atividades de docência e de gestão educacional dos sistemas de ensino e das unidades escolares de educação básica, nas diversas etapas e modalidades de educação (educação infantil, ensino fundamental, ensino médio, educação de jovens e adultos, educação especial, educação profissional e técnica de nível médio, educação escolar indígena, educação do campo, educação escolar quilombola e educação a distância), e possuem a formação mínima exigida pela legislação federal das Diretrizes e Bases da Educação Nacional. As novas DCNs definem que a valorização desses profissionais compreende a articulação entre formação inicial, formação continuada, carreira, salários e condiçóes de trabalho.

Nessa direção, em consonância com a legislação em vigor, as DCNs sinalizam que compete aos sistemas de ensino e às instituiçóes a responsabilidade pela garantia de políticas de valorização dos profissionais do magistério da educação básica, que devem ter assegurada sua formação, além de plano de carreira, de acordo com a legislação vigente, e uma preparação para atuar nas etapas e modalidades da educação básica e seus projetos de gestão, conforme definido na base comum nacional e nas diretrizes de formação, segundo o PDI, PPI e PPC da instituição de educação superior, em articulação com os sistemas e redes de ensino de educação básica.

Visando contribuir com a melhoria dos processos pedagógicos as novas DCNs sinalizam que as formas de organização e gestão da educação básica, incluindo as orientaçóes curriculares, os entes federados e os respectivos sistemas de ensino e instituiçóes educativas deverão garantir adequada relação numérica professor/educando, levando em consideração as características dos educandos, do espaço físico, das etapas e modalidades da educação básica e do projeto pedagógico e curricular.

As novas DCNs definem, ainda, nas disposiçóes transitórias que: os cursos de formação de professores que se encontram em funcionamento deverão se adaptar à Resolução proposta no prazo de 2 (dois) anos; os pedidos de autorização para funcionamento de curso em andamento serão restituídos aos proponentes para que sejam feitas as adequaçóes necessárias; os processos de avaliação dos cursos de licenciatura serão realizados pelo órgão próprio do sistema e acompanhados por comissóes próprias de cada área; os cursos de formação inicial de professores 
para a educação básica em nível superior, em cursos de licenciatura, organizados em áreas interdisciplinares, serão objeto de regulamentação suplementar. Por fim, visando a materialização das novas Diretrizes Curriculares Nacionais para a formação inicial e continuada dos profissionais da educação básica proposta e sua consequente Resolução, define-se a revogação das disposições em contrário, em especial a Resolução CNE/CP no 2, de 26 de junho de 1997, a Resolução CNE/CP $n^{\circ} 1$, de 30 de setembro de 1999, a Resolução CNE/CP no 1 , de 18 de fevereiro de 2002 e suas alterações, a Resolução CNE/CP no 2, de 19 de fevereiro de 2002 e suas alterações, a Resolução no 1 , de 11 de fevereiro de 2009, e a Resolução no 3, de 7 de dezembro de 2012.

\section{Considerações finais: o PNE, as DCNs e a organicidade das políticas e gestão da educação}

O Conselho Nacional de Educação, cumprindo o seu papel de órgão de Estado, ao instituir a Comissão Bicameral para a Formação dos profissionais do magistério da educação básica e avançar na proposição de novas diretrizes curriculares para a formação inicial e continuada dos profissionais do magistério, a partir de estudos, pesquisas, debates e audiências públicas, com diversificados interlocutores, sinaliza importantes elementos para a política nacional para a formação dos profissionais da educação.

Como delineamos, ao longo do texto, as referidas DCNs se direcionam a formação inicial e continuada dos profissionais do magistério da educação básica, a partir da definição de base comum nacional articulada a essas dinâmicas formativas. Nessa direção, advoga a institucionalização de um projeto de formação pelas Instituições de Educação Superior, priorizando as Universidades, por meio da efetiva articulação dessas IES com os entes federados, seus sistemas e redes, instituições de educação superior e instituições de educação básica, sem descurar da efetiva participação dos fóruns permanentes de formação e demais instâncias como conselhos nacional, distrital, estaduais e municipais e respectivos fóruns. Entendemos que esta perspectiva articulada a centralidade conferida à formação dos profissionais do magistério da educação básica pode contribuir para a superação da dicotomia entre teoria e prática, bacharelado e licenciatura, bem como, propiciar efetiva articulação entre as políticas e dinâmicas de organização, gestão e financiamento da educação, suas instituições e seus atores.

Na direção de políticas mais orgânicas, as novas diretrizes curriculares ratificam princípios e buscam contribuir para a melhoria da formação inicial e continuada os profissionais do magistério ao definir a base comum nacional, demanda histórica de entidades do campo educacional, como referência para a valorização dos profissionais da educação no bojo da instituição de um subsistema 
de valorização dos profissionais da educação envolvendo, de modo articulado, questôes e políticas atinentes a formação inicial e continuada, carreira, salários e condiçóes de trabalho. As diretrizes aprovadas enfatizam a necessária articulação entre educação básica e superior, bem como, a institucionalização de projeto próprio de formação inicial e continuada dos profissionais do magistério da educação básica, por parte das instituiçóes formadoras, tendo por eixo concepção formativa e indutora de desenvolvimento institucional que redimensiona a formação desses profissionais a partir de concepção de docência que inclui o exercício articulado nos processos ensino e aprendizagem e na organização e gestão da educação básica.

Importante destacar que novos desafios se colocam ao campo da formação, envolvendo os entes federados, os sistemas de ensino, as instituições, os fóruns permanentes de apoio a formação dos profissionais da educação, as entidades cientifico-acadêmicas e sindicais e, em especial, as instituições que se encarregam da formação na perspectiva de propostas e projetos mais orgânicos para a formação inicial e continuada como delineado nas novas DCNs, objeto de discussão neste artigo.

Articulado a esse processo, como previsto no Plano Nacional de Educação, faz-se necessário instituir o Sistema Nacional de Educação, consolidar Política Nacional para a formação dos profissionais da educação, estabelecer diretrizes curriculares nacionais para a carreira e garantir novos recursos visando cumprir a meta de $10 \%$ do PIB para a educação, entre outros, como processos articulados e fundamentais a maior organicidade para as políticas e gestão da educação nacional.

\section{Notas}

1. O presente artigo recupera parte significativa do texto do Parecer CNE/CP 02/2015, de minha relatoria, e faz alguns apontamentos adicionais.

2. Importante destacar que a Proposta do MEC para a referida política foi lançada, em 24/6/15, e aberto processo de consulta pública por 30 dias.

3. Resolução CNE/CP no 2, de 26 de junho de 1997, da Resolução CNE/CP no 1, de 30 de setembro de 1999, da Resoluçáo CNE/CP no 1, de 18 de fevereiro de 2002 e suas alteraçóes, a Resolução CNE/CP no 2, de 19 de fevereiro de 2002 e suas alteraçóes, entre outros.

4. Conforme Ata CNE/CP no 14/2012, a Comissão Bicameral passou a contar com os seguintes membros: José Fernandes de Lima, Benno Sander, Francisco Aparecido Cordão, José Francisco Soares, Luiz Fernandes Dourado, Luiz Roberto Alves, Malvina Tania Tuttman, Maria Izabel de Azevedo Noronha, Nilma Lino Gomes, José Eustáquio Romão e Sérgio Roberto Kieling Franco, ocasião em que houve manifestação de conselheiros no sentido de que a Comissão fosse mais efetiva. Posteriormente, por meio da Portaria CNE/CP no 1, 28 de janeiro de 2014, a Comissão passou a contar com os seguintes membros: José Fernandes de Lima (Presidente), Benno Sander, Francisco Aparecido Cordão, José Francisco Soares, Luiz Fernandes Dourado, Luiz Roberto Alves, Malvina Tania Tuttman, Maria Izabel de Azevedo Noronha, Nilma Lino Gomes, José Eustáquio Romão, Sérgio Roberto Kieling Franco e Raimundo Moacir Mendes Feitosa. 
5. Nessa direção, a Comissão procedeu a estudos e discussóes de subtemáticas a partir da apresentação de estudos demandados pela Comissão e de textos elaborados pelos conselheiros. Em 2013, a Comissão aprovou documento preliminar, ratificando a decisão de propor DCNs conjuntas para a Formação Inicial e Continuada dos Profissionais do Magistério da Educação Básica, e o submeteu ao crivo de especialistas, entidades da área, Secretarias do Ministério da Educação, Capes, Inep, entre outros. Em seguida, a Comissão estruturou minuta base de resolução e iniciou o processo de discussão ampliada dos documentos.

6. A Comissão passou a contar com os seguintes conselheiros: José Fernandes de Lima (CEB/CNE), Presidente, Luiz Fernandes Dourado (CES/CNE), Relator, Antonio Carlos Caruso Ronca (CEB/ $\mathrm{CNE}$ ), Francisco Aparecido Cordão (CEB/CNE), Gilberto Gonçalves Garcia (CES/CNE), Luiz Roberto Alves (CEB/CNE), Malvina Tania Tuttman (CEB/CNE), Márcia Angela da Silva Aguiar (CES/CNE), Nilma Lino Gomes (CEB/CNE), José Eustáquio Romão (CES/CNE), Raimundo Moacir Mendes Feitosa (CEB/CNE) e Sérgio Roberto Kieling Franco (CES/CNE), membros. Importante salientar que em 2015, após assumir a SEPIR, a Conselheira Nilma Lino Gomes desligou-se do CNE.

7. Dentre outros encontros, destaca-se que em maio de 2012 foi realizado o Seminário sobre Formação de Professores no Conselho Nacional de Educação, oportunidade em que participaram das mesas de debates as Secretarias do MEC, Capes, Anfope, CNTE, Anped, Consed, Undime, Forumdir, CRUB, Andifes, Conif, Abruc, Abruem, Anpae, Cedes, Conselho Técnico-Científico da Educação Básica, Forprop, Associação Brasileira de Educação Musical, Associação Nacional de História, Sociedade Brasileira de Geografia, SBPC, Associaçáo dos Pesquisadores em Ensino de Ciências, Sociedade Brasileira de Física, Sociedade Brasileira de Educação Matemática e Sociedade Brasileira de Química. Além disso, em 31 de março de 2014, houve reunião ampliada da Comissão Bicameral de Formação de Professores com convidados como Secretarias do MEC, FNE, Anfope, Anpae, Anped, Cedes, Forumdir, na qual o relator da matéria apresentou minuta de texto referente às Diretrizes Curriculares. Ainda, nos dias 15 e 16 de julho de 2015, foi realizada reunião técnica com a presença do Conif, Abruem, Abruc, Andifes, Consed, CNTE, Anfope, Uncme e FNCE. Ademais, em 2015, foram realizadas três reuniôes técnicas da Comissão Bicameral: em 26/1/2015 e 4/5/2015, com representantes das Secretarias do MEC e Capes, e em 9/3/2015, uma reuniáo técnica ampliada que contou com a presença de representantes do Forumdir, CNTE, Anfope, Cedes, FNCE, Contee, Uncme e Anped, além do MEC e Capes.

8. Nos últimos dois anos, além de reuniôes de trabalho, seminários, discussões sobre as DCNs de Formação/CNE foram efetivadas na Universidade de São Paulo/FE/USP, UFRN/FE; UNICAMP/ FE; UnB/Decanato de Graduação; UFG/Fórum de Licenciatura; UnB/ForGrad Centro-Oeste; PUC/GO/Escola Humanidades; UFAM/ForGrad/Norte; UFRGS/Faculdade de Educação/Conselho Estadual; UFG/Catalão; UFCG; UFPba; Conselho Estadual de Educação de Goiás/UFG/IFGOIANO; UFPE; XVII Endipe; UFBA/Forumdir; Anfope; Capes/Pasem; UCB; UFPA/IE, dentre outros.

9. É relevante ressaltar que o Parecer, bem como a minuta de Resolução, encontram-se em consonância com a legislação pertinente: - Constituição da República Federativa do Brasil, de 1988; - Lei no 9.394, de 20 de dezembro de 1996 (Lei de Diretrizes e Bases da Educaçáo Nacional); - Lei no 11.494, de 20 de junho de 2007, que regulamenta o Fundeb; - Lei no 11.502, de 11 de julho de 2007, que modifica as competências e a estrutura organizacional da Fundação Coordenação de Aperfeiçoamento de Pessoal de Nível Superior - CAPES; - Lei no 11.738, de 16 de julho de 2008, que regulamenta o piso salarial profissional nacional para os profissionais do magistério público da educação básica; - Lei no 12.796, de 4 de abril de 2013, que altera a Lei no 9.394/1996; - Lei no 13.005, de 25 de junho de 2014, que aprova o Plano Nacional de Educação, especialmente as metas (15 a 18) e suas estratégias direcionadas aos profissionais do magistério da Educaçáo Básica; Decreto no 6.755, de 29 de janeiro de 2009, que institui a Política Nacional de Formação de Profissionais do Magistério da Educação Básica, disciplina a atuação da Capes no fomento a programas de formação inicial e continuada, e dá outras providências; Resoluções e Pareceres do CNE sobre a temática, bem como as deliberaçóes da Conae (2010 e 2014). 
Diretrizes curriculares nacionais para a formação inicial e continuada

10. Importante situar que muitos sistemas de ensino, redes e instituições de educação básica vem desenvolvendo políticas e projetos de formação continuada. A esse respeito ver GATTI, BARRETO, ANDRÉ, 2011.

\section{Referências}

AGUIAR, M. A. S. O movimento dos educadores e sua valorização profissional: o que há de novo em anos recentes? Revista Brasileira de Política e Administração da Educação, Porto Alegre, v. 25, n. 2, p. 249-262, 2009.

AGUIAR, M. A. S. et al. Diretrizes curriculares do curso de pedagogia no Brasil: disputas de projetos no campo da formação do profissional da educação. Educ. Soc., vol. 27, n. 96, p. 819-842, out. 2006, ISSN 0101-7330.

AIRES, C. J. Relatório do estudo analítico sobre as politicas públicas de gestão democrática do ensino público da educação básica. Brasília: CNE, UNESCO, 2015.

ALVES, L. Direitos humanos como tema global. S. Paulo: Perspectiva, 1994.

ALVES, L. R. Princípios e Fundamentos para uma Política Nacional de Formaçâo de Professores da Educação Básica na vigência do PNE e no interior do SNE. Brasília: CNE, 2014.

. Imagens e representaçôes dolda professor(a) (educador/a?) na imprensa brasileira e no documento-referência para Conae 2014. Brasília: CNE, 2013.

. Reflexóes sobre formação inicial e continuada de professores/as - articulaçôes possíveis. Brasília: CNE, 2013a.

ANDRÉ, M. et al. Estado da arte da formação de professores no Brasil. Educ. Soc., vol. 20, no 68, p. 301-309, dez. 1999, ISSN 0101-7330.

ANDRÉ, M. Políticas de valorização do trabalho docente no Brasil: algumas questôes. Ensaio: aval. pol. públ. educ., vol. 23, n. 86, p. 213-230, fev. 2015, ISSN 0104-4036.

ARROYO, M. G. Os movimentos sociais e a construção de outros currículos. Educar em Revista. Curitiba: Editora UFPR. 1, n. 55, p. 48, jan/mar. 2015.

ASSOCIAÇÃO NACIONAL DE PESQUISA E PÓS-GRADUAÇÃO EM EDUCAÇÃO (Anped). Análise do Documento "Projeto de Resolução que define as Diretrizes Curriculares Nacionais para a formação inicial e continuada", 2014, 8p. (mimeo).

ASSOCIAÇÃO NACIONAL DE POLÍTICA E ADMINISTRAÇÃO DA EDUCAÇÃO (Anpae). Análise do documento: "Projeto de Resolução", que Define as Diretrizes Curriculares Nacionais para a formaçáo inicial e continuada, 2014, 4p. (mimeo).

ASSOCIAÇÃO NACIONAL PELA FORMAÇÃO DOS PROFISSIONAIS DA EDUCAÇÃO (Anfope). Análise do Documento "Projeto de Resolução que define as Diretrizes Curriculares Nacionais para a formação inicial e continuada", 2014, 8p. (mimeo).

BORDAS, M. C. Documento A: Projeto 914BRA1123 - CNE - Politicas Educacionais: Subsidio à Formulação e Avaliação de Políticas Educacionais Brasileiras. 2009a. Impresso. 
BORDAS, M. C. Documento B: Avaliação da implantação das diretrizes curriculares nacionais para a formação de professores nos cursos de licenciatura. Projeto 914BRA1123-CNE - Políticas Educacionais: Subsídio à Formulação e Avaliação de Políticas Educacionais Brasileiras. 2009b. Impresso.

BRASIL. Plano Nacional de Educação em Direitos Humanos. Secretaria de Direitos Humanos da Presidência da República, 2006.

. Conselho Nacional de Educação. Define as Diretrizes Curriculares Nacionais para a formação inicial em nível superior (cursos de licenciatura, cursos de formação pedagógica para graduados e cursos de segunda licenciatura) e para a formação continuada. Resolução CNE/CP n. 02/2015, de $1^{\circ}$ de julho de 2015. Brasília, Diário Oficial [da] República Federativa do Brasil, seção 1, n. 124, p. 8-12, 02 de julho de 2015. Disponível em: http://pesquisa.in.gov.br/imprensa/jsp/visualiza/index.jsp?data=02/07/2015\&jornal=1\& pagina $=8 \&$ total Arquivos $=72$.

. Conselho Nacional de Educação. Diretrizes Curriculares Nacionais para a Educação Escolar Quilombola na Educação Básica. Resolução CNE/CEB no 8, de 20 de novembro de 2012. Brasília, Diário Oficial [da] República Federativa do Brasil, 21 de novembro de 2012, Seção 1, p. 26.

. Conselho Nacional de Educação. Diretrizes Curriculares Nacionais para a Educação Profissional Técnica de Nível Médio. Resolução CNE/CEB no 6, de 20 de setembro de 2012. Brasília, Diário Oficial [da] República Federativa do Brasil, 21 de setembro de 2012, Seção 1, p. 22.

. Conselho Nacional de Educação. Diretrizes Curriculares Nacionais para a Educação Escolar Indígena na Educação Básica. Resolução CNE/CEB no 5, de 22 de junho de 2012. Brasília, Diário Oficial [da] República Federativa do Brasil, 25 de junho de 2012, Seção 1, p. 7.

. Conselho Nacional de Educação. Diretrizes Curriculares Nacionais para a Educação Ambiental. Resoluçâo CNE/CP no 2, de 15 de junho de 2012. Brasília, Diário Oficial [da] República Federativa do Brasil,18 de junho de 2012, Seção 1, p. 70

Conselho Nacional de Educação. Diretrizes Nacionais para a Educação em Direitos Humanos. Resoluçấo CNE/CP no 1, de 30 de maio de 2012. Brasília, Diário Oficial [da] República Federativa do Brasil, 31 de maio de 2012, Seção 1, p. 48.

Conselho Nacional de Educação. Diretrizes para o atendimento de educação escolar para populações em situação de itinerância. Resolução CNE/CEB no 3, de 16 de maio de 2012. Brasília, Diário Oficial [da] República Federativa do Brasil, 17 de maio de 2012, Seção 1, p. 14.

Conselho Nacional de Educação. Diretrizes Curriculares Nacionais para o Ensino Fundamental de 9 anos. Resolução CNE/CEB no 7, de 14 de dezembro de 2010. Brasília, Diário Oficial [da] República Federativa do Brasil, 15 de dezembro de 2010, Seção 1, p. 34, 2010. 
BRASIL. Conselho Nacional de Educação. Diretrizes Curriculares Nacionais Gerais para a Educação Básica. Resolução CNE/CEB no 4, de 13 de julho de 2010. Brasília, Diário Oficial [da] República Federativa do Brasil, 14 de julho de 2010, Seção 1, p. 824, 2010.

. Conselho Nacional de Educação. Diretrizes Operacionais para a Educação de Jovens e Adultos nos aspectos relativos à duração dos cursos e idade mínima para ingresso nos cursos de EJA; idade mínima e certificação nos exames de EJA; e Educação de Jovens e Adultos desenvolvida por meio da Educação a Distância. Resolução CNE/CEB no 3, de 15 de junho de 2010. Brasília, Diário Oficial [da] República Federativa do Brasil,16 de junho de 2010, Seção 1, p. 66.

Conselho Nacional de Educação. Diretrizes Nacionais para a oferta de educação para jovens e adultos em situaçáo de privaçáo de liberdade nos estabelecimentos penais. Resolução CNE/CEB no 2, de 19 de maio de 2010. Brasília, Diário Oficial [da] República Federativa do Brasil, 20 de maio de 2010, Seção 1, p. 20.

. Conselho Nacional de Educação. Diretrizes Curriculares Nacionais para a Educação Infantil. Resolução CNE/CEB no 5, de 17 de dezembro de 2009. Brasília, Diário Oficial [da] República Federativa do Brasil, 18 de dezembro de 2009, Seçáo 1, p. 18, 2009.

- Conselho Nacional de Educação. Diretrizes Operacionais para o Atendimento Especializado na Educação Básica, modalidade Educação Especial. Resolução CNE/CEB no 4, de 2 de outubro de 2009. Brasília, Diário Oficial [da] República Federativa do Brasil, 5 de outubro de 2009, Seção 1, p. 17.

Conselho Nacional de Educação. Escassez de professores no Ensino Médio: Propostas estruturais e emergenciais. Relatório produzido pela Comissão Especial instituída para estudar medidas que visem a superar o déficit docente no Ensino Médio (CNE/ CEB), Brasília, 2007.

. Conselho Nacional de Educação. Solicitação de esclarecimento sobre as Resoluçóes CNE/CP nos 1/2002, que institui Diretrizes Curriculares Nacionais para a Formação de Professores da Educação Básica, em nível superior, curso de licenciatura, de graduação plena, e $2 / 2002$, que institui a duração e a carga horária dos cursos de licenciatura, de graduação plena, de Formação de Professores da Educação Básica, em nível superior. Parecer CNE/CES no 15, de 13 de dezembro de 2005. Brasília, Diário Oficial [da] República Federativa do Brasil, 15 de maio de 2006.

. Conselho Nacional de Educação. Diretrizes Curriculares Nacionais para o Ensino Médio. Resoluçấo CNE/CEB no 1, de 3 de fevereiro de 2005. Brasília, Diário Oficial [da] República Federativa do Brasil, 11 de março de 2005.

. Conselho Nacional de Educação. Diretrizes Curriculares Nacionais para a Educação das Relaçôes Étnico-Raciais e para o Ensino de História e Cultura Afro-Brasileira e Africana. Resolução CNE/CP no 1, de 17 de junho de 2004. Brasília, Diário Oficial [da] República Federativa do Brasil, 22 de junho de 2004, Seção 1, p. 11. 
BRASIL. Conselho Nacional de Educação. Diretrizes Operacionais para a Educação Básica nas Escolas do Campo. Resolução CNE/CEB no 1, de 3 de abril de 2002. Brasília, Diário Oficial [da] República Federativa do Brasil, 9 de abril de 2002. Seção 1, p. 32.

. Conselho Nacional de Educação. Dá nova redação ao Parecer CNE/CP 21/2001, que estabelece a duração e a carga horária dos cursos de Formação de Professores da Educação Básica, em nível superior, curso de licenciatura, de graduação plena. Parecer CNE/ CP no 28, de 2 de outubro de 2001. Brasília, Diário Oficial [da] República Federativa do Brasil, 18 de janeiro de 2002, Seção 1, p. 31.

. Conselho Nacional de Educação. Diretrizes Curriculares Nacionais para o Ensino Médio. Resolução CNE/CEB no 3, de 26 de junho de 1998. Brasília, Diário Oficial [da] República Federativa do Brasil, 05 de agosto de 1998.

Ministério da Educaçáo. Documento Final da Conferência Nacional de Educação (Conae). Brasília, MEC, 2010. Disponível em http://conae.mec.gov.br/images/stories/ pdf/pdf/documetos/documento_final_sl.pdf. Acesso em janeiro de 2013.

. Ministério da Educação. Documento Final da Conferência Nacional de Educação (Conae). Brasília, MEC, 2014. Disponível em http://fne.mec.gov.br/images/doc/DocumentoFina240415.pdf. Acesso em janeiro de 2015.

BRZEZINSKI, I. (Org.). LDB/1996 contemporânea: contradiçôes, tensôes, compromissos. São Paulo: Cortez, 2014.

. Sujeitos sociais coletivos e a política de formação inicial e continuada emergencial de professores: contradições vs. conciliaçôes. Educação \& Sociedade, v. 35, n 129, p. 1241 1259, out./dez. 2014.

. Anfope em movimento: 2008-2010. Brasília: Liber Livro/Anfope/Capes, 2011.

CANDAU, V. M. Direitos humanos, educação e interculturalidade: as tensôes entre igualdade e diferença. Rev. Bras. Educ., vol. 13, n. 37, p.45-56, abr. 2008, ISSN 1413-2478

CANDAU, V. M.; SACAVINO, S. Educar em direitos humanos: construir democracia. Rio de Janeiro: DP\&A, 2000.

CANDAU, V. M.; LEITE, M. S. A didática na perspectiva multi/intercultural em ação: construindo uma proposta. Cad. Pesqui., vol. 37, n. 132, p.731-758, dez. 2007, ISSN 0100-1574.

CAPES. Relatório de Gestão DEB 2009-2013. Brasília: Capes, 2014.

CENTRO ACADÊMICO PAULO FREIRE. Avaliação crítica da proposta do núcleo docente estruturante para o novo projeto político pedagógico do curso de pedagogia da faculdade de educação da UFG. Goiânia, mimeo, 2014.

CENTRO DE ESTUDOS EDUCAÇÃO E SOCIEDADE (Cedes). Análise do Documento "Projeto de Resolução que define as Diretrizes Curriculares Nacionais para a formação inicial e continuada". 2014, 6p.

CNTE. Políticas e gestão da educação básica: concepçôes e proposições da CNTE. Brasília: CNTE, 2013. 
Diretrizes curriculares nacionais para a formação inicial e continuada

COÊLHO, I. M. Diretrizes Curriculares e Ensino de Graduação. Estudos, n. 22, abr. de 1998.

COMPARATO, F. K. A afirmaçâo histórica dos direitos humanos. 2a. ed. S. Paulo: Saraiva, 2001.

CONFERAÇÃO NACIONAL DOS TRABALHADORES EM EDUCAÇÃO (CNTE). Análise do Documento "Projeto de Resolução que define as Diretrizes Curriculares Nacionais para a formação inicial e continuada”. 2014, 6p.

CONSELHO NACIONAL DAS INSTITUIÇÓES DA REDE FEDERAL DE EDUCAÇÃO PROFISSIONAL, CIENTÍFICA E TECNOLÓGICO (Conif). Política Nacional de formação de professores para a educação básica brasileira, 2014, 4p.

CURY, C. R. J. Reforma universitária na nova lei de diretrizes e bases da educação nacional? Cadernos de Pesquisa. São Paulo, Fundação Carlos Chagas, n. 101, p. 3-19, 1997.

DAMIES, O. T. As Diretrizes Curriculares Nacionais Gerais para Educação Básica e a Formação de Professores: Subsídios para o Processo de Avaliação e Revisão das Orientaçóes Sobre Formação de Professores Para Educação Básica. PROJETO 914BRZ1001-4 CNE/ UNESCO: Subsídio à Formulação e Avaliação de Políticas Educacionais Brasileiras. Brasília: Unesco, 2012.

DOSSIÊ. Formaçẫo de Professores: impasses e perspectivas. Revista Retratos da Escola, Brasília, CNTE, v. 2, n. 2/3, 2008.

\section{3}

. Educação e Diversidade. Revista Retratos da Escola Brasília, CNTE, v. 7, n. 13,

DOURADO, L. F. A Conferência Nacional de Educação e a Construção de Políticas de Estado. In. FRANÇA, M. e MOMO, M. (Orgs.). Processo Democrático participativo. A construção do PNE. Campinas, SP: Mercado das Letras, 23-40, 2014.

. A Base Comum Nacional e a formação dos professores. Brasília, CNE, 2013.

. A formação de professores e a base comum nacional: questôes e proposiçóes para o debate. RBPAE, v. 29, n. 2, p. 367-388, maio/ago. 2013a.

. Sistema Nacional de Educação, Federalismo e os obstáculos ao direito à educação básica. Educ. Soc., vol. 34, n. 124, p. 761-785, jul./set. 2013.

. Documento C: Consolidação das normas do CNE sobre formação de professores. PROJETO 914BRA1123 - CNE. Políticas Educacionais: Subsídio à Formulação e Avaliação de Políticas Educacionais Brasileiras. Brasília: MEC, 2009.

GUIMARÁES, J. A. Apresentação. A articulação entre a Pós-Graduação e a Educação Básica. Brasília, Capes, RBPG: v. 9, n. 16, 2012.

OLIVEIRA, J. F.; DOURADO, L.F.; GUIMARÃES, V. S. A reformulação dos cursos de licenciatura da UFG: construindo um projeto coletivo. Goiânia, Inter-Ação, v. 1, 2003, p.195-204.

FREITAS, H. C. L de. PNE e formação de professores: contradições e desafios. Revista Retratos da Escola, Brasília, v. 8, n. 15, p. 427-446, jul./dez. 2014. 
FREITAS, H. C. L de. A (nova) política de formação de professores: a prioridade postergada. Educ.\& Soc., v. 28, n.100, p.1 203-1230, out. 2007.

. Formação de professores no Brasil: 10 anos de embate entre projetos de formação. Educ. \& Soc., v. 23, n. 80, p. 136-167, set. 2002.

FÓRUM NACIONAL DE DIRETORES DE FACULDADES, CENTRO DE EDUCAÇÃO OU EQUIVALENTES DAS UNIVERSIDADES PÚBLICAS BRASILEIRAS (Forumdir). Análise do Documento "Projeto de Resolução que define as Diretrizes Curriculares Nacionais para a formação inicial e continuada”. 2014, 4p.

GATTI, B.A; BARRETO, E.S.S; ANDRÉ, M.E.D.A. Políticas Docentes no Brasil. Estado da Arte. Brasil: Unesco, 2011, 300p.

GATTI, B.A. Formação de professores no Brasil: características e problemas. Educ. \& Soc., v. 31, n. 113, p. 1355-1379, dez. 2010.

- Análise das políticas públicas para formação continuada no Brasil, na última década. Rev. Bras. Educ., v. 13, n. 37, p. 57-70, abr., 2008.

GOMES, N. L. Formação de Professores e Diversidade. Brasília: CNE, 2013.

INSTITUTO NACIONAL DE ESTUDOS E PESQUISAS EDUCACIONAIS ANÍSIO TEIXEIRA (Inep). Perfil da docência no Ensino Médio Regular. Brasília: Diretoria de Estatísticas Educacionais, MEC/Inep/Deed, 2015.

. Relatório Nacional da Pesquisa TALIS. Brasília: Diretoria de Estatísticas Educacionais, MEC/Inep/Deed, 2014.

LEITE, Y.U.; LIMA, V. M. M. Cursos de pedagogia no Brasil: o que dizem os dados do INEP/MEC? Ensino em Revista, Uberlândia, v. 17, n. 1, p. 69-93, jan./jun.2010.

LIMA, J. F. Questóes e provocaçōes sobre a formação de professores. Brasília: CNE, 2013.

Reflexóes sobre formação inicial e continuada de professores/as - articulaçôes possiveis. Brasília: CNE, 2013a.

MOREIRA, A. F. B; CANDAU, V. B. Educação escolar e cultura(s): construindo caminhos. Rev. Bras. Educ., n. 23, p. 156-168, ago. 2003.

NÓVOA, A. Formação de professores e profissão docente. In: NÓVOA, A. (Coord.). Os professores e sua formação. Lisboa: Dom Quixote, 1992. Disponível em http://repositorio. ul.pt/bitstream/10451/4758/1/FPPD_A_Novoa.pdf. Acesso em janeiro de 2014.

OLIVEIRA, D. A. (Coord.) et al. Estudio sobre criterios de calidad y mejora de la formación docente del Mercosur. Informe Brasil. Programa de Apoyo al Sector Educativo del Mercosur (PASEM), 2013.

OLIVEIRA, D. A. Regulação educativa na América Latina: repercussóes sobre a identidade dos trabalhadores docentes. Ensino em Revista, n. 44, p. 209-227, dez 2006.

PEIXOTO, A. J. (Org.). Formação de professores, políticas, concepções e perspectivas. Goiânia: Alternativa, v. 1, p. 69-80, 2001. 
PIMENTA, S. G.; ALMEIDA, M. I. (Orgs.). Estágios Supervisionados na Formação Docente. 1a. ed. São Paulo: Cortez Editora, 2014.

PIMENTA, S. G.; LIBÂNEO, J. C. Formação de profissionais da educação: visão crítica e perspectiva de mudança. Revista Educação e Sociedade, Campinas, v. 68, p. 239-277, 2000.

RODINO, A. M. et al. (Orgs.). Cultura e educação em direitos humanos na América Latina. João Pessoa: UFPB, 2014.

SANDER, B. Docência e Formação Docente. Tendências internacionais e significados locais. Brasília: CNE, 2013.

SCHEIBE, L. Valorização e formação dos professores para a educação básica: questôes desafiadoras para um novo Plano Nacional de Educação. Educ. \& Soc., v .31, n.112, p. 981-1000, jul./set., 2010.

SCHEIBE, L.; AGUIAR, M. A. S. Formação de profissionais da educação no Brasil: o curso de pedagogia em questão. Educ. \&. Soc., v. 20, n. 68, p. 220-238, out./dez. 1999.

SCHEIBE, L. Documento Técnico B: Avaliação da Implantação das Novas Diretrizes Nacionais para os Cursos de Pedagogia. PROJETO 914BRA1123 - CNE - Políticas Educacionais: Subsídio à Formulação e Avaliação de Políticas Educacionais Brasileiras. 2009. Impresso.

SILVA, K. A. P. C.; LIMONTA, S. (Orgs.). Formação de Professores na Perspectiva Crítica: resistência e utopia. Brasília: Editora da Universidade de Brasília, 2015.

SOUSA, N. H. B. de. Comitês Estaduais de Educação em Direitos Humanos no Brasil: desafios e perspectivas. In: SILVA, A. T. R. da. Leituras críticas em educação e direitos humanos. Brasília: Liber Livro/Alia Opera, 2014.

TEIXEIRA, A. O problema da formação do magistério. Documenta, n. 62, p. 11, nov. 1966.

TUTTMAN, M. T. A sociedade desejada. Qual? Brasília: CNE, 2013.

UFG/FACULDADE DE EDUCAÇÃO. Contribuição da FE/UFG à Proposta de Resolução dos debates das DCN de Formação de Professores. Goiânia, UFG/FE, 2015, 3p.

UFG/FÓRUM DE LICENCIATURAS. Contribuição do Fórum de Licenciaturas da UFG ao debate das DCN de Formação de Professores. Goiânia, UFG, 2015, 2p.

UFRN/DEPARTAMENTO DE EDUCAÇÃO. Contribuição do Fórum de Licenciaturas da UFG ao debate das DCN de Formação de Professores. Goiânia, UFG, 2015.

VIEIRA, J.D. Valorização dos profissionais: carreira e salários. Revista Retratos da Escola, Brasília, v. 8, n. 15, p. 409-426, jul./dez. 2014.

Recebido em 25 de junho de 2015.

Aprovado em 26 de junho de 2015.

DOI: http://dx.doi.org/10.1590/ES0101-73302015151909 